\title{
Validation of an automated adenoma detection rate calculating system for quality improvement of colonoscopy
}

\author{
Dae Kyung Sohn', Il Won Shin², Jeonghwa Yeon ${ }^{3}$, Jin Yoo ${ }^{3}$, Byung Chang Kim¹, Bun Kim¹, Chang Won Hong', \\ Kyung Su Han ${ }^{1}$
}

${ }^{1}$ Center for Colorectal Cancer, Research Institute and Hospital, National Cancer Center, Goyang, Korea

IInformation Technology Team, Research Institute and Hospital, National Cancer Center, Goyang, Korea

${ }^{3}$ Endoscopy Room, Research Institute and Hospital, National Cancer Center, Goyang, Korea

\begin{abstract}
Purpose: This study aimed to validate an automated calculating system developed for determining the adenoma detection rate (ADR).

Methods: To calculate the automated ADR, the data linking processes were as follows: (1) matching the selected colonoscopy results with the pathological results, (2) matching the polyp number from colonoscopy with that from pathology and confirming the histopathological results of each colonic polyp, and (3) confirming the histopathological results, especially the adenoma status of each colonic polyp. To verify the accuracy of the automated ADR calculating system, we manually calculated the ADR for 3 months through medical record review. Accuracy was calculated by measuring the error rate for each value. The cause of error was analyzed by additional order and chart review.

Results: After excluding 318 cases, 2,543 patients (1,351 men and 1,192 women; median age, 57.9 years) who underwent colonoscopy were included in this study. When the automated calculating system was used, polyps were found in 1,336 cases $(52.6 \%)$ and adenomas were found in 1,003 cases $(39.4 \%)$. When the manual calculating system was used, polyps were found in 1,327 cases $(52.2 \%)$ and adenomas were found in 1,003 cases $(39.4 \%)$. The accuracies of the polyp detection rate and ADR according to the automated calculating system were $99.3 \%$ and $100 \%$, respectively.

Conclusion: We developed a system to automatically calculate the ADR by extracting hospital electronic medical record results and verified that it provided satisfactory results. It may help to improve colonoscopy quality.

[Ann Surg Treat Res 2019;97(6):319-325]
\end{abstract}

Key Words: Colon, Colonoscopy, Colorectal neoplasms, Electronic health records, Quality improvement

\section{INTRODUCTION}

Colorectal cancer is the third most common cancer worldwide, with the second highest incidence rate in Korea. According to the Korea Central Cancer Registry, 26,790 cases of colorectal cancer were identified in 2015, accounting for $12.5 \%$ of all cancers, and the incidence rate per 100,000 population is 52.6 cases [1]. More than $80 \%$ of colorectal cancer cases progress through the adenoma-adenocarcinoma process over 5-10 years, so the incidence of colorectal cancer can be reduced by detecting and removing precancerous lesions [2]. Therefore, it is most important to determine accurate and efficient screening methods for the early detection of colorectal cancer. Colonoscopy has been recognized as an excellent and very
Received July 16, 2019, Revised October 24, 2019,

Accepted October 25, 2019

Corresponding Author: Dae Kyung Sohn

Center for Colorectal Cancer, Research Institute and Hospital, National

Cancer Center, 323 Ilsan-ro, Ilsandong-gu, Goyang 10408, Korea

Tel: +82-31-920-1636, Fax: +82-31-920-0002

E-mail: gsgsbal@ncc.re.kr

ORCID: https://orcid.org/0000-0003-3296-6646
Copyright (C) 2019, the Korean Surgical Society

(c) Annals of Surgical Treatment and Research is an Open Access Journal. All articles are distributed under the terms of the Creative Commons Attribution NonCommercial License (http://creativecommons.org/licenses/by-nc/4.0/) which permits unrestricted non-commercial use, distribution, and reproduction in any medium, provided the original work is properly cited. 
effective method for colorectal cancer screening since previous studies reported that the incidence of colorectal cancer was reduced by approximately 76\%-90\% upon colonoscopy and polypectomy [3-5].

The removal of polyps by colonoscopy can decrease mortality due to colon cancer [5,6]. However, colorectal cancer cannot be completely prevented by colonoscopy, and colorectal cancer may occur in patients who have undergone colonoscopy. Generally, colorectal cancer that occurs before the next recommendation for colonoscopy is referred to as "postcolonoscopy colorectal cancer" or "interval colorectal cancer," and it accounts for approximately $7.2 \%-9.0 \%$ of cases $[7,8]$. The most common causes of interval cancers are missed lesions, incomplete polyp resection, and a rapidly progressing new lesion [7]. The most important method to reduce the risk of lesions is to improve the quality of colonoscopy. The indexes of colonoscopy quality include but are not limited to the cecal intubation rate, endoscopic withdrawal time, adenoma detection rate (ADR), and polyp detection rate (PDR) [7,9,10]. Among these indexes, ADR has been considered the main index for evaluating the quality of colonoscopy in recent years and is related to the risk of interval cancer [7,11]. According to the United States Multidisciplinary Guideline for Colorectal Cancer Care, the rates of finding adenomas in asymptomatic men and women older than 50 years are at least $25 \%$ and $15 \%$, respectively $[2,12]$. Although the importance of ADR as a quality control for colonoscopy is widely recognized, it is difficult to monitor in real time because pathological results are obtained within a few days after colonoscopy. Additionally, it is difficult to match the result of colonoscopy and that of pathology because the form of the reporting system of each examination is very different. Especially, in many hospitals, endoscopic findings and pathologic results are recorded in a narrative format rather than a specific data format $[13,14]$. Therefore, to overcome this limitation, some researchers attempted to match pathologic results of endoscopic polyps using natural language processing (NLP) techniques [15-18]. However, the matching system using the NLP method has a disadvantage, that is, the error rate can increase when it is widely used [17,18].

Therefore, to increase the accuracy and the compatibility to various systems, we tried to develop an automated ADR calculating system by inputting the endoscopic results and polyp data according to a specific format and then matching the pathologic results. In this study, we aimed to verify the accuracy of data extraction and the results of the automated ADR calculating system using information from electronic medical records (EMRs).

\section{METHODS}

\section{Study setting}

Since 2018, the National Cancer Center has been promoting the use of the ADR as a part of an endoscopic quality management improvement program. An automated calculating system has been developed by linking polyp data and pathological results from EMRs. The processes for linking were as follows: (1) matching the selected colonoscopy results with the pathology results, (2) matching the polyp number of the colonoscopy result with that of the pathology result and confirming the histopathological results of each colonic polyp, and (3) confirming the histopathological results, especially the adenoma status, of each colonic polyp.

A total of 2,861 patients who underwent colonoscopy between June 1, 2018, and August 31, 2018, were included. Of these, 318 patients were excluded, including those in whom the procedure did not involve the cecum, such as sigmoidoscopy, foreign body removal, bleeding control, ballooning/stenting, and endoscopic submucosal dissection. Finally, 2,543 patients were included for analysis in this study.

\section{Entering the colonoscopy results into the EMR}

The following colonoscopy results were recorded in the EMR during a specified window and inputted according to a specified format: date of the test, name of the test, purpose of the examination, registration number of the patient, sex, age, history of endoscopy, sedative drugs, bowel cleansing methods, degree of cleansing, reaching location, cecal intubation time, total examination time, examination summary, endoscopic diagnosis, and doctors. If colorectal polyps were found during the examination and a biopsy or polypectomy was performed, the following additional data were entered: number of polyps; location, shape, and size of each polyp; type of treatment; and complications (Fig. 1).

\section{Inputting the pathological results into the EMR}

If a histopathologic examination was requested during colonoscopy, the following data were entered: number and location of polyps, treatment history, and gross and histopathological findings. The biopsy results for each polyp were described individually by labeling the polyp number as "\#Number," and 2 blank lines were drawn between the results for each polyp (Fig. 2).

\section{Extraction and matching of data}

To calculate the detection rate of polyps, the results of colonoscopy for 3 months were examined. The following examination names and codes, which were defined by the health insurance system, were extracted: colonoscopy examination name and code (colonoscopy [E7660], mucosal resection and submucosal 


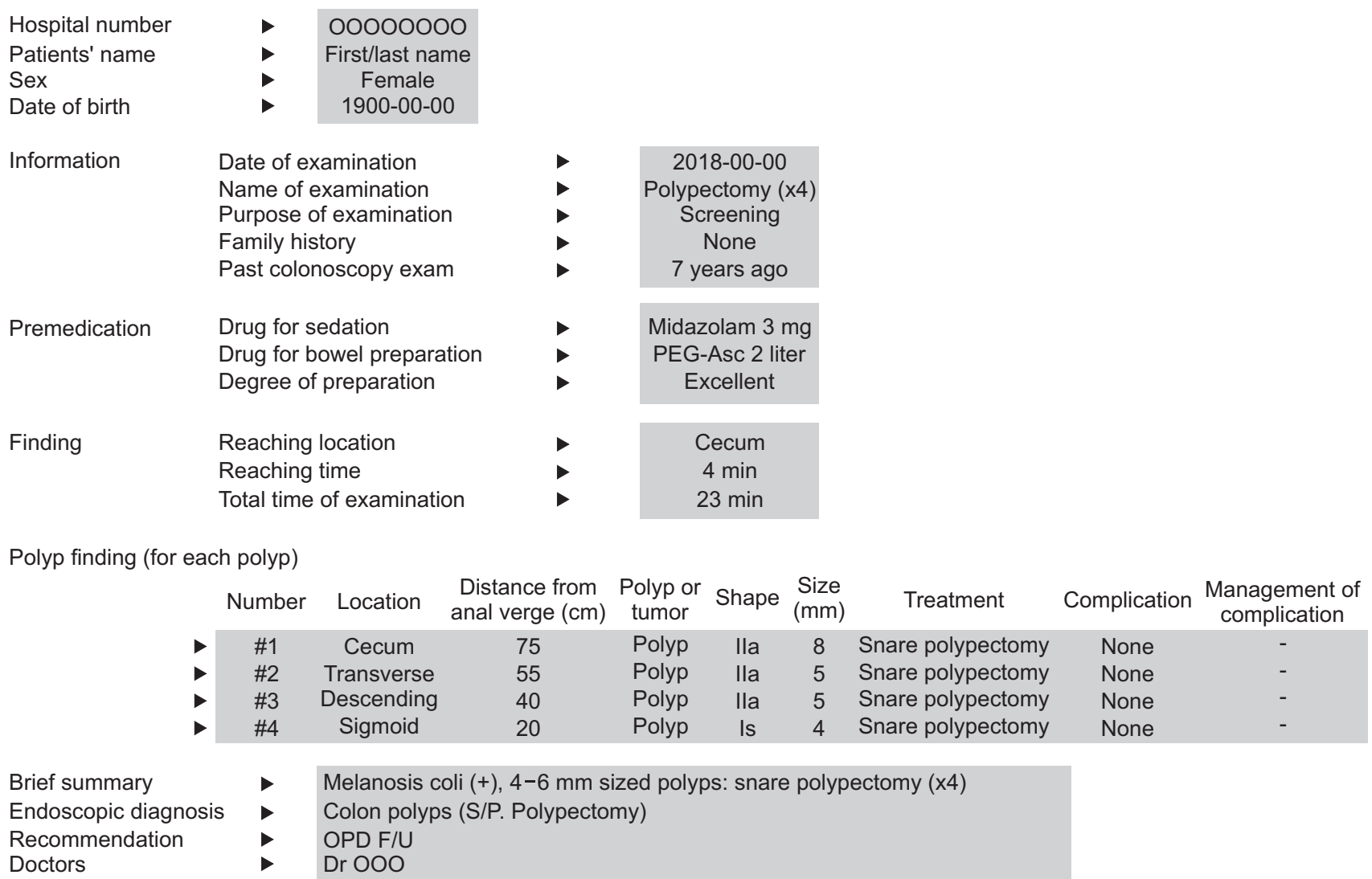

Fig. 1. Colonoscopy report form.

Number of pathology: S 000000000

Clinical diagnosis: cecal polyp, colon polyps

The received tissues are 4 parts

$\# 1$. One polypectomy tissue fixed to formalin is $0.7 \times 0.4 \mathrm{~cm}$ in size.

\#2. Three polypectomy tissues fixed to formalin, the largest being $0.5 \times 0.3 \mathrm{~cm}$.

\#3. One polypectomy tissue fixed to formalin is $0.4 \times 0.3 \mathrm{~cm}$ in size.

\#4. Two polypectomy tissues fixed to formalin, the size of the large one is $0.3 \times 0.3 \mathrm{~cm}$.

Micro (4 HE)

Diagnosis:

\#1. Cecum, polyp, Ila, snare polypectomy: hyperplastic polyp

\#2. Colon, transverse, polyp, Ila, snare polypectomy: tubular adenoma, low grade

\#3. Colon, descending, polyp, Ila, snare polypectomy: tubular adenoma, low grade

\#4. Colon, sigmoid, polyp, Is, snare polypectomy: tubular adenoma, low grade

Fig. 2. Pathology report form. resection [Q7703], polypectomy [Q7701 and Q7702]), and pathological examination name and code (level B [C5602], level C [number of paraffin blocks: less than 10, C5603], and level D [number of paraffin blocks: 10 or more, C5604]). The following examination or procedure names were excluded from the analysis: endoscopic submucosal dissection (QX706), colonic sublingual stenting (Q7692), colonoscopic removal of foreign body (Q7670), colonoscopic bleeding control (Q7680), and sigmoidoscopy and its related procedures (E7670 and E7680).

To match the results of each colon polyp and the pathological results, the pathological number of the designated pathological examination code that was received on the date of the test was started with "S," and the designated main collection site was the colon (e.g., the following terms were included in the main collection site name: ileum, rectum, anus, rectal, cecum, colo, anal, appe, and ileocecal). To calculate the ADR, the following terms were searched for in the pathological results and defined as adenoma positivity: adenoma, serrated polyp, or adenocarcinoma.

\section{Calculating the PDR and ADR}

PDR, ADR, PDR in screenees, and ADR in screenees were defined as follows: 
Table 1. Patients' characteristics and results of colonoscopies

\begin{tabular}{lc}
\hline \multicolumn{1}{c}{ Variable } & Value \\
\hline Sex, male:female & $1,351: 1,192$ \\
Age (yr), median (range) & $57.9(11-91)$ \\
Total No. of colonoscopies, n (\%) & 2,543 \\
No. of cases with any polyp & $1,338(52.6)$ \\
No. of cases with any adenoma & $1,003(39.4)$ \\
No. of screening colonoscopies, n $(\%)$ & 866 \\
No. of cases with any polyp & $420(48.5)$ \\
No. of cases with any adenoma & $310(35.8)$
\end{tabular}

- $\mathrm{PDR}=$ (number of examinations with polyps/total number of examinations) $\times 100$

- $\mathrm{ADR}=$ (number of examinations with adenomas/total number of examinations) $\times 100$

- $\mathrm{PDR}$ in screenees $=$ PDR in asymptomatic persons who had undergone their first colonoscopy or who had been examined more than 5 years ago

- $\mathrm{ADR}$ in screenees $=\mathrm{ADR}$ in asymptomatic persons who had undergone their first colonoscopy or who had been examined more than 5 years ago

The results of PDR, ADR, PDR in screenees, and ADR in screenees calculated using our automated calculating system were compared with manually calculated results through medical record review. Accuracy was calculated by measuring the error rate for each value. The cause of error was analyzed by additional order and chart review. All statistical analyses were performed with Microsoft Office Excel 2010 (Microsoft Corp., Redmond, WA, USA).

\section{Validation of the automated ADR calculating system}

To verify the accuracy of the developed automated ADR calculating system (video clip), we manually calculated the ADR for the same period (from June 1, 2018 to August 31, 2018) by reviewing patients' medical records. The automated system was designed to calculate polyp/ADR by parsing pathologic reports and matching polyp information in the colonoscopic reports. For the manual calculation, a research nurse confirmed the pathologic and colonoscopic results from the electrical medical records. This retrospective, single-institutional study was reviewed and approved by the Institutional Review Board (IRB approval number: NCC2018-0244). All investigations were conducted according to the principles in the Declaration of Helsinki. The need for informed consent was waived by the IRB.

\section{RESULTS}

Overall, 2,543 colonoscopies were performed in 1,351 male
Table 2. Polyp detection rate and adenoma detection rate according to patients' age distribution

\begin{tabular}{ccccccc}
\hline Age $(y r)$ & $\begin{array}{c}\text { No. of } \\
\text { colono- } \\
\text { scopies }\end{array}$ & PDR & ADR & $\begin{array}{c}\text { No. of } \\
\text { scree- } \\
\text { nees }\end{array}$ & $\begin{array}{c}\text { PDR in } \\
\text { scree- } \\
\text { nees }\end{array}$ & $\begin{array}{c}\text { ADR in } \\
\text { scree- } \\
\text { nees }\end{array}$ \\
\hline $10-19$ & 2 & 100 & 50 & 1 & 100 & 0 \\
$20-29$ & 26 & 34.6 & 15.4 & 14 & 28.6 & 14.3 \\
$30-39$ & 114 & 23.7 & 12.3 & 70 & 24.3 & 11.4 \\
$40-49$ & 482 & 38.2 & 27.0 & 221 & 39.4 & 26.2 \\
$50-59$ & 843 & 50.9 & 37.8 & 293 & 49.1 & 36.5 \\
$60-69$ & 662 & 61.6 & 45.6 & 170 & 57.1 & 42.9 \\
$70-79$ & 355 & 68.2 & 57.2 & 85 & 71.8 & 62.4 \\
$80-89$ & 57 & 59.6 & 49.1 & 12 & 75.0 & 75.0 \\
$\geq 90$ & 2 & 100 & 100 & 0 & - & - \\
\hline
\end{tabular}

PDR, polyp detection rate; $\mathrm{ADR}$, adenoma detection rate.

and 1,192 female patients, with a median age of 57.9 (range, 1191) years (Table 1). The indications of colonoscopy were cancer screening in 905 patients, polypectomy surveillance in 283 , gastrointestinal symptom in 844 , surveillance after colorectal cancer treatment in 367, positive occult blood in 34, and other in 110 . When using the automated calculating system, polyps were found in 1,336 cases (PDR, 52.6\%). Adenomas were found in 1,003 cases (ADR, 39.4\%). The PDR and ADR according to patient age are presented in Table 2. The median PDR and median ADR according to each colonoscopist were $48.1 \%$ (range, $27.3 \%-69.7 \%$ ) and $38.0 \%$ (range, 3.1\%-55.8\%), respectively.

Among 866 screening colonoscopies, 420 revealed the presence of polyps (PDR in screenees, 48.5\%). Adenomas were found in 310 cases (ADR in screenees, 35.8\%). The median PDR and median ADR in screenees according to each colonoscopist were $47.8 \%$ (range, $0 \%-73.8 \%$ ) and $37.1 \%$ (range, $0 \%-66.7 \%$ ), respectively.

When using the manual calculating system, polyps were found in 1,327 cases (PDR, 52.2\%). Adenomas were found in 1,003 cases by manual calculation (ADR, 39.4\%). The accuracy rates of PDR and ADR on using the automated calculating system were $99.3 \%$ and $100 \%$, respectively. Errors in the PDR calculations were included in 9 cases where (1) polyps were not removed but recorded on an endoscopic recording sheet, (2) the test order code was entered incorrectly, or (3) colonoscopy was performed twice within 1 week.

\section{DISCUSSION}

As the incidence of colonoscopy for colorectal cancer screening has increased, the importance of quality control for colonoscopy is growing. The adenoma rate is known to be the most important factor in colonoscopy quality control, but it is difficult to manage because of the difficulty in connecting endoscopic results with pathological results. We successfully 
developed an automated calculating system for determining the ADR in colonoscopy, and in this study, we verified its ability to calculate the ADR.

Screening programs for colorectal cancer are currently being performed worldwide $[2,3]$. There is sufficient evidence to support that adenomatous polyps can be detected by colonoscopy and that colonoscopic polypectomy can reduce the incidence of cancer [4,5,19]. Although colonoscopy is the gold standard for current colorectal cancer screening, the effect of colonoscopy is related to its quality. Among the various quality indicators, the most commonly used one is the ADR, which is a percentage of the population that has been found to have at least one adenoma or adenocarcinoma during screening colonoscopy. There is also strong evidence to support the correlation between ADR and interval colorectal cancer [11,12].

Although there is consensus on the importance of colonoscopy quality management through ongoing monitoring of ADRs, many hospitals are unable to monitor the ADR because of the difficulty in managing colonoscopy results and pathological results together. To overcome these limitations, a method of using the PDR instead of the ADR has been proposed $[8,20]$. However, if the PDR is poorly applied, indiscriminate removal of minute polyps that do not have clinical significance increases the cost of medical treatment. Therefore, each hospital should strive to apply the ADR rather than the PDR, and the expert societies should support its efforts.

To increase the ADR, the indicators should be managed through continuous monitoring, and education on how to observe adenomas and precisely and safely remove them is needed [21]. Additionally, sufficient time should be provided to physicians so that they can easily and accurately inspect each part of the colon [22]. To ensure that sufficient time is provided, the number of tests per hour can be limited. It is important to recognize that identifying and eliminating adenomas through accurate colonoscopy are the best ways to reduce the incidence of preventable colorectal cancer and reduce unnecessary testing and medical costs.

Many efforts have been made to develop a program that automatically calculates the ADR. However, the most difficult part of this system configuration is the exact matching of endoscopic and pathological results for each polyp. In particular, many hospitals are still not using structured endoscopic and pathological result input forms. Imler et al. [15] reported a high accuracy for the identification of adenomas and hyperplastic polyps using NLP in a Veterans Administration Medical Center. Then, they evaluated their NLP pipeline across 13 Veterans Administration Medical Centers and continued to show a high accuracy [16]. Raju et al. [17] supplemented this literature through accurately detecting screening colonoscopies using NLP as well as accurately identifying adenomas and sessile serrated polyps in a university hospital that used the
Endoworks endoscopy reporting system. Additionally, Nayor et al. [18] reported using the NLP pipeline to calculate the ADR using data from Epic, Provation, and Sunquest PowerPath, 3 widely used electronic health record systems in the United States. They used the natural language search method to search for adenomas and serrated polyps in the pathological results, and then they automatically calculated the ADR by linking these results with the information from the endoscopic results. Unlike these systems, our system has the difference in not only the calculating method of ADR per colonoscopy, but also the linking method of pathological results for individual polyps.

To further improve the automated ADR calculating system, efforts of both clinical doctors and pathologists are needed to develop a structured data input system. For example, the errors identified in the automatic ADR calculating system in our study were in cases in which the prescription order was changed after the colonoscopy examination and the detected polyps were not removed but recorded. In these cases, the endoscopic results did not match the pathological results. Since most of these errors occurred in the step of inputting the test results, it is necessary to try to reduce the errors through continuous education and feedback. In addition, it is necessary to develop a verification system that automatically confirms the input errors and immediately provides notifications about them, as pathologic reports are still written manually. When 2 colonoscopies were performed within a short period, it was confirmed that an error occurred in matching between the endoscopic result and pathological result because the date of endoscopy does not always coincide with the pathological request date. In general, if colonoscopy is completed late in the afternoon, a request for a pathological examination is made on the next day. If the endoscopic examination is performed on a weekend or a holiday, the difference may be a maximum of 3-5 days. These errors may be resolved by looking for other types of matching items that can be corrected rather than by relying on matching by checking the date. These improvements can be achieved if endoscopists and pathologists as well as laboratory nurses and system developers work together.

In this study, ADRs varied according to endoscopist. This may be because of the diversity in the purpose of colonoscopy, including screening, to make a diagnosis after obtaining positive fecal occult blood test results or upon appearance of symptoms, and follow-up after polypectomy. In addition, the participating doctors included surgeons and endoscopists specialized in screening colonoscopy. However, the number of patients participating in this study is limited, which makes it difficult to perform further analysis to determine the difference in ADR by subject or by occupational group. Additional data will be needed for further study.

This study has some limitations. First, additional system improvements are needed to address some of the problems 
found in this study. Simplification and automation of the result input system are also needed in consideration of user convenience. Second, it is necessary to continuously give feedback to the endoscopists and to check whether the low ADR improved [23]. Third, in this study, as well as in asymptomatic screenees, many colonoscopies required symptomatic polypectomy surveillance and a positive fecal occult blood test result. Therefore, the results were much higher than those of the ADR guidelines proposed previously $[2,10]$. Thus, it is necessary to pay attention to the interpretation of ADR results and compare them with those in other studies. In this study, we additionally analyzed the results of "ADR in screenees," which was ADR in asymptomatic persons who had undergone their first colonoscopy or who had been examined more than 5 years ago. Finally, it is necessary to standardize the developed system so that it can be applied to other hospital systems.
In conclusion, although not perfect, our automated calculating system for determining the ADR by extracting hospital EMR system results was verified and showed satisfactory results. If the development of such a system becomes more widespread, ADR can be easily monitored to improve the quality of colonoscopy.

\section{CONFLICTS OF INTEREST}

No potential conflict of interest relevant to this article was reported.

\section{ACKNOWLEDGEMENTS}

This project was supported by a grant from the National Cancer Center (grant number: NCC-1710070).

\section{REFERENCES}

1. Jung KW, Won YJ, Kong HJ, Lee ES; Community of Population-Based Regional Cancer Registries. Cancer statistics in Korea: incidence, mortality, survival, and prevalence in 2015. Cancer Res Treat 2018;50:303-16.

2. Levin B, Lieberman DA, McFarland B, Smith RA, Brooks D, Andrews KS, et al. Screening and surveillance for the early detection of colorectal cancer and adenomatous polyps, 2008: a joint guideline from the American Cancer Society, the US Multi-Society Task Force on Colorectal Cancer, and the American College of Radiology. CA Cancer J Clin 2008; 58:130-60.

3. Sohn DK, Kim MJ, Park Y, Suh M, Shin A, Lee HY, et al. The Korean guideline for colorectal cancer screening. J Korean Med Assoc 2015;58:420-32.

4. Kahi CJ, Imperiale TF, Juliar BE, Rex DK. Effect of screening colonoscopy on colorectal cancer incidence and mortality. Clin Gastroenterol Hepatol 2009;7:770-5.

5. Winawer SJ, Zauber AG, Ho MN, O'Brien MJ, Gottlieb LS, Sternberg SS, et al. Prevention of colorectal cancer by colonoscopic polypectomy. The National Polyp Study Workgroup. N Engl J Med 1993;329:
1977-81.

6. Zauber AG, Winawer SJ, O'Brien MJ, Lansdorp-Vogelaar I, van Ballegooijen M, Hankey BF, et al. Colonoscopic polypectomy and long-term prevention of colorectal-cancer deaths. N Engl J Med 2012;366:687-96.

7. Kaminski MF, Regula J, Kraszewska E, Polkowski M, Wojciechowska U, Didkowska J, et al. Quality indicators for colonoscopy and the risk of interval cancer. $\mathrm{N}$ Engl J Med 2010;362:1795-803.

8. Kaminski MF, Wieszczy P, Rupinski M, Wojciechowska U, Didkowska J, Kraszews$\mathrm{ka} E$, et al. Increased rate of adenoma detection associates with reduced risk of colorectal cancer and death. Gastroenterology 2017;153:98-105.

9. Samadder NJ, Curtin K, Tuohy TM, Pappas L, Boucher K, Provenzale D, et al. Characteristics of missed or interval colorectal cancer and patient survival: a population-based study. Gastroenterology 2014;146:950-60.

10. Deutsch JC. Colonoscopy quality, quality measures, and a natural language processing tool for electronic health records. Gastrointest Endosc 2012;75:1240-2.

11. Lee TJ, Rutter MD, Blanks RG, Moss SM,
Goddard AF, Chilton A, et al. Colonoscopy quality measures: experience from the NHS Bowel Cancer Screening Programme. Gut 2012;61:1050-7.

12. Corley DA, Jensen CD, Marks AR, Zhao WK, Lee JK, Doubeni CA, et al. Adenoma detection rate and risk of colorectal cancer and death. N Engl J Med 2014;370:1298306.

13. Yun JH, Ahn SJ, Kim Y. Development of clinical contents model markup language for electronic health records. Healthc Inform Res 2012;18:171-7.

14. de Lusignan S. Informatics as tool for quality improvement: rapid implementation of guidance for the management of chronic kidney disease in England as an exemplar. Healthc Inform Res 2013;19:915.

15. Imler TD, Morea J, Kahi C, Imperiale TF. Natural language processing accurately categorizes findings from colonoscopy and pathology reports. Clin Gastroenterol Hepatol 2013;11:689-94.

16. Imler TD, Morea J, Kahi C, Sherer EA, Cardwell J, Johnson CS, et al. Multi-center colonoscopy quality measurement utilizing natural language processing. Am J Gastroenterol 2015;110:543-52. 
17. Raju GS, Lum PJ, Slack RS, Thirumurthi S, Lynch PM, Miller E, et al. Natural language processing as an alternative to manual reporting of colonoscopy quality metrics. Gastrointest Endosc 2015;82:5129.

18. Nayor J, Borges LF, Goryachev S, Gainer VS, Saltzman JR. Natural language processing accurately calculates adenoma and sessile serrated polyp detection rates. Dig Dis Sci 2018;63:1794-800.

19. Lieberman DA, Rex DK, Winawer SJ, Giardiello FM, Johnson DA, Levin TR. Guidelines for colonoscopy surveillance after screening and polypectomy: a consensus update by the US Multi-Society Task Force on Colorectal Cancer. Gastroenterology 2012;143:844-57.

20. Francis DL, Rodriguez-Correa DT, Buchner A, Harewood GC, Wallace M. Application of a conversion factor to estimate the adenoma detection rate from the polyp detection rate. Gastrointest Endosc 2011;73:4937.

21. Kim JH, Choi YJ, Kwon HJ, Park SJ, Park MI, Moon W, et al. Simple colonoscopy reporting system checking the detection rate of colon polyps. World J Gastroenterol
2015;21:9380-6.

22. Oh JR, Han KS, Hong CW, Kim BC, Kim B, Park SC, et al. Colonoscopy learning curves for colorectal surgery fellow trainees: experiences with the 15-year colonoscopy training program. Ann Surg Treat Res 2018;95:169-74.

23. Lin OS, Kozarek RA, Arai A, Gluck M, Jiranek GC, Kowdley KV, et al. The effect of periodic monitoring and feedback on screening colonoscopy withdrawal times, polyp detection rates, and patient satisfaction scores. Gastrointest Endosc 2010; 71:1253-9. 